04

\title{
Влияние растягивающих нагрузок на напряжение пробоя тонких пленок
}

\author{
(C) А.М. Пашаев, А.Х. Джанахмедов, А.А. Алиев \\ Национальная академия авиации, \\ AZ1045 Баку, Азербайджан \\ e-mail: a.aliyev@naa.az
}

Поступило в Редакцию 9 апреля 2019 г.

В окончательной редакции 9 апреля 2019 г.

Принято к публикации 27 мая 2019 г.

Рассмотрена проблема электрического пробоя внешних лакокрасочных покрытий воздушных судов. Показано, что образование канала пробоя в диэлектрической пленке связано с разрывом макромолекул полимера в растянутых зонах. На примере полиэфируретановой пленки экспериментально выявлено, что с ростом растягивающих нагрузок напряжение пробоя (электрическая прочность) экспоненциально убывает.

Ключевые слова: воздушное судно, лакокрасочное покрытие, пробой, электрическая прочность, электрический разряд, электрическая эрозия, растягивающие напряжения, полиэфируретан.

DOI: 10.21883/JTF.2020.01.48661.159-19

\section{Введение}

Во время полета и вибраций поверхность воздушного судна (BC) относительно окружающей атмосферы приобретает некоторую разность потенциалов. Возникающее электрическое поле может привести к появлению электрических разрядов по поверхности внешних лакокрасочных покрытий (ЛКП) [1].

Существующие варианты защиты поверхности ВС от атмосферного электричества (помимо применения различных разрядников, токосъемников и т.п.) сводятся к обеспечению повышения поверхностной проводимости внешнего ЛКП [2,3]. Но, несмотря на это, в эксплуатации неоднократно фиксировались случаи пробоя ЛКП из-за электрических разрядов по поверхности ВС.

Электрическими разрядами, содержащими от одного до нескольких десятков импульсов, поражаются все типы ВС на любой высоте и в любую погоду, в том числе вне грозовой обстановки. Поэтому возникновение подобных повреждений в пределах срока службы ЛКП может рассматриваться как неизбежное явление и требует от покрытия достаточной электрической прочности. Поскольку ресурс ЛКП также определяется временем непрерывной работы до образования повреждения (в том числе пробоя), становится актуальной проблема оценки его способности выдерживать попадание электрического разряда без критических разрушений.

Когда напряженность поля превосходит некоторое критическое значение, ЛКП теряет свойства электроизоляционного материала и происходит его пробой. Значение напряжения, при котором происходит пробой диэлектрика, называется пробивным напряжением $U_{\mathrm{bd}}$, а соответствующее значение напряженности поля электрической прочностью диэлектрика $E_{\mathrm{bd}}$. Электрическая прочность $E_{\mathrm{bd}}(\mathrm{MV} / \mathrm{m})$ определяется пробивным напряжением, отнесенным к толщине диэлектрика в месте пробоя $h[4]$ :

$$
E_{\mathrm{bd}}=U_{\mathrm{bd}} / h
$$

При поражении ЛКП электрическим разрядом повреждения имеют вид локальных кратеров, образующихся в результате сублимации и точечного микровзрыва материала ЛКП [5]. Сквозные пробои связаны с возникновением в толще диэлектрического материала проводящего канала из-за его точечного проплавления и выгорания с последующей карбонизацией и возникновением проводимости.

В работе [6] авторами были рассмотрены особенности пробоя тонких (нано- и микроразмерных) полимерных пленок при комнатной температуре в режиме подъема напряжения с постоянной скоростью. Выявлено, что пробой происходит в полях с напряженностью $(2-6) \cdot 10^{6} \mathrm{~V} / \mathrm{cm}$, при этом наблюдается экспоненциальная зависимость электрической долговечности (времени с момента приложения постоянного по величине напряжения до пробоя образца) от средней напряженности поля.

Имеющиеся данные позволяют сделать вывод о том, что причиной электрического разрушения полимерных диэлектриков является образование в толще материала полостей или зон с пониженной плотностью и разрывом макромолекул, где может возникнуть ударная ионизация, приводящая к пробою [1].

Под действием внешней растягивающей силы энергия разрыва связи снижается и делает возможным дальнейший разрыв макромолекулы [7-9].

Из приведенных данных следует, что электрическое разрушение тонких полимерных пленок является следствием постепенного локального накопления повреждений, завершающегося пробоем в наиболее растянутых точках. 


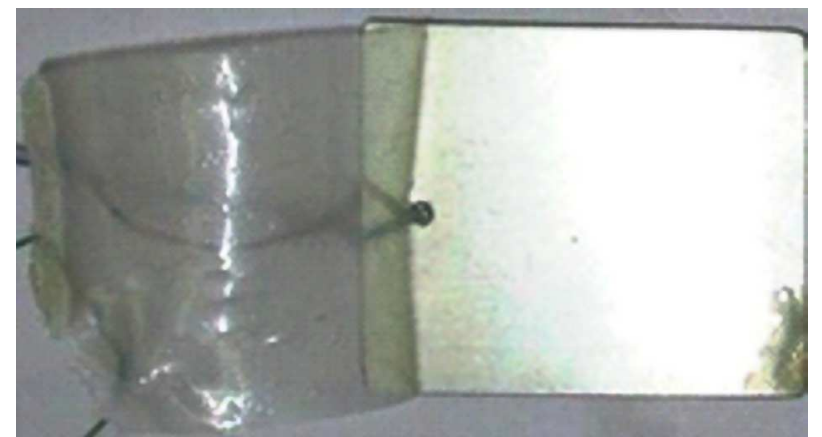

Образец с отслоившейся пленкой ПЭУЛ после выдержки в ацетоне в течение $24 \mathrm{~h}$.

Очевидно, что ЛКП, нанесенное на поверхность, также воспринимает все ее механические нагрузки, способные привести к нарушению его сплошности (микроразрывам). Во внешнем ЛКП ВС постоянно присутствуют статические и динамически меняющиеся растягивающие напряжения, среди которых можно выделить усадочные напряжения, напряжения от полетных нагрузок и набегающих потоков воздуха. Наличие неравномерных полей растягивающих напряжений означает возникновение в пленке областей с различной степенью сжатия, т.е. относительно неравномерной плотностью. Последующее попадание электрического разряда в растянутое покрытие может привести к его пробою $[10,11]$.

Целью настоящей работы является выявление зависимостей между пробивным напряжением и уровнем растягивающих нагрузок ${ }^{1}$ в ЛКП для последующего прогнозирования его стойкости к электрическим разрядам в условиях эксплуатационного уровня механического нагружения.

\section{Материалы и методы}

В качестве исследуемого лакокрасочного материала (ЛКМ) был выбран полиэфируретановый лак (ПЭУЛ) с пределом прочности при разрыве $\sigma_{B}=8 \mathrm{MPa}$ [12].

Для испытания применяли образцы пленки ПЭУЛ в форме прямоугольника $20 \times 150 \mathrm{~mm}$ толщиной $100 \mu \mathrm{m}$. Для получения пленки лак приготавливали согласно инструкции производителя и наносили равномерным слоем толщиной $100 \mu \mathrm{m}$ на дюралюминиевую пластину $200 \times 200 \mathrm{~mm}$ [13]. После отвердевания покрытия образец выдерживали в ацетоне в течение $24 \mathrm{~h}$. В результате пленка ПЭУЛ легко отслаивалась от подложки (см. рисунок) и обрезалась до указанных размеров; всего было получено 12 образцов.

Испытания образцов пленки на пробой проводились на специальном стенде, предусматривающем растяжение

\footnotetext{
${ }^{1}$ Во избежание терминологической путаницы между понятиями „механическое напряжение“ и „электрическое напряжение“ в качестве синонима для первого из них будем использовать термин „механиче-

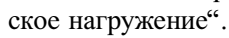

Средние значения напряжения пробоя (электрической прочности) пленки ПЭУЛ толщиной $h=100 \mu \mathrm{m}$ при ее растяжении в размере $0.2 \sigma_{B}, 0.4 \sigma_{B}, 0.6 \sigma_{B}$ и $0.8 \sigma_{B}$ от величины разрывающего напряжения $\left(\sigma_{B}\right)$

\begin{tabular}{c|c}
\hline $\begin{array}{c}\text { Нагрузка } \\
\text { в долях } \sigma_{B}\end{array}$ & $\begin{array}{c}\text { Среднее значение напряжения про- } \\
\text { боя }(\mathrm{kV}) / \text { /лектрическая прочность }(\mathrm{MV} / \mathrm{m})\end{array}$ \\
\hline 0 & $45.3 / 453$ \\
$($ без нагрузки) & $35.4 / 354$ \\
0.2 & $30.3 / 303$ \\
0.4 & $24.3 / 243$ \\
0.6 & $21.9 / 219$ \\
0.8 &
\end{tabular}

пленочного образца и подачу напряжения. Растяжение пленки проводилось в соответствии с [14] на разрывной машине с электромеханическим приводом [15]. Усилие прилагалось в размере $0,20,40,60$ и $80 \%$ от величины разрывающего напряжения $\left(\sigma_{B}\right)$. На растянутую пленку с помощью высоковольтной установки в соответствии с требованиями [16-18] подавалось высокое напряжение, плавно повышаемое вплоть до наступления пробоя.

\section{Результаты испытаний и их обсуждение}

Было испытано по 3 образца для каждого значения растягивающей нагрузки и затем по формуле (1) вычислялось среднее арифметическое значение напряжения пробоя (округленное до десятых) и электрической прочности (округленное до целых значений). Результаты экспериментов представлены в таблице.

В проведенных испытаниях при воздействии электрического разряда удалось оценить электрическую прочность образцов ЛКП с различным уровнем растягивающих механических напряжений. Как следует из таблицы, с ростом растягивающей нагрузки напряжение пробоя пленки ПЭУЛ монотонно убывает и может быть приближенно выражено экспоненциальной зависимостью вида

$$
U_{\mathrm{bd}} \sim U_{\mathrm{bd}}^{0} \cdot \exp (-x),
$$

где $U_{\mathrm{bd}}^{0}-$ напряжение пробоя при отсутствии растягивающей нагрузки, $x-$ растягивающая нагрузка в долях от $\sigma_{B}(0.2 \ldots 0.8)$.

Очевидно, что для значений электрической прочности зависимость будет иметь тот же характер

$$
E_{\mathrm{bd}} \sim E_{\mathrm{bd}}^{0} \cdot \exp (-x),
$$

где $E_{\mathrm{bd}}^{0}-$ электрическая прочность при отсутствии растягивающей нагрузки.

Как уже было отмечено выше, экспоненциальная зависимость электрической долговечности тонких полимерных пленок от средней напряженности поля уже была выявлена авторами [6]. В описанном эксперименте также наблюдается экспоненциальная зависимость электрической прочности, что указывает на сходный механизм 
зарождения и развития пробоя и в случае механически растягиваемых пленок.

Полученное выражение достаточно условно,но позволяет прогнозировать работоспособность ЛКП. Зная уровень эксплуатационных нагрузок в ЛКП и параметры характерных атмосферных разрядов [19], можно спрогнозировать его стойкость к пробоям и значительно сузить круг потенциально пригодных ЛКМ, сократив тем самым временные и материальные затраты.

\section{Выводы}

- Рассмотрена проблема электрического пробоя внешних ЛКП ВС в контексте образования в полимерной пленке зон с пониженной плотностью и разрывом макромолекул.

- На примере ПЭУ пленки проведен анализ процесса воздействия высокого напряжения на растянутую пленку ЛКП и ее пробой при $0,20,40,60$ и 80\% от величины предела прочности на растяжение $\left(\sigma_{B}\right)$.

- Показано,что с ростом растягивающей нагрузки напряжение пробоя (электрическая прочность) ПЭУ пленки экспоненциально убывает, что позволяет спрогнозировать стойкость материала к электроразрядам в конкретных эксплуатационных условиях.

\section{Конфликт интересов}

Авторы заявляют об отсутствии конфликта интересов.

\section{Список литературы}

[1] Привердиев Э.С., Джсанахмедов А.Х., Вольченко А.И., Фидровская Н.Н., Вольченко Н.А., Скрыпнык В.С. Узлы трения в машиностроении. Баку: Элм, 2018. 440 с.

[2] Соболевская Е.Г., Борисов Р.К., Прохоров Е.Н. // Межвузовский сборник научных трудов ЧТУ им. И.Н. Ульянова, Чебоксары. 1989. С. 71-79.

[3] Соболевская Е.Г., Гуняев Г.М., Митрофанова Е.А. Электрофизические характеристики проводящих полимерных композиционных материалов при воздействии сильных импульсных токов и молниезащита углепластиковых конструкций. Тезисы доклада на международной конференции по композитам. АН СССР. Серия „Перспективные материалы“, М. 1990. С. 230-256.

[4] Каверинский В.С., Смехов Ф.М. Электрические свойства лакокрасочных материалов и покрытий. М.: Химия, 1990. C. $14-15$.

[5] Гуляев И.Н., Гуняева А.Г., Раскутин А.Е., Федотов М.Ю., Сорокин К.В. Молниезащита и встроенный контроль для конструкций из ПКМ (Спец. выпуск). Труды ВИАМ. М. 2013. № 4.

[6] Закревский В.А., Сударь Н.Т. // ФТТ. 2005. Т. 47. Вып. 5. C. $931-936$.

[7] Закревский В.А., Слуцкер А.И. // ВМС. 1984. Т. 26 (А). № 6. C. 1201-1206.
[8] Kao K.C. New theory of electrical discharge and breakdown in lowmobility condensed insulators // J. Appl. Phys. 1984. Vol. 55. N 3. P. 752-755.

[9] Lebey T., Laurent C. // J. Appl. Phys. 1990. Vol. 68. N 1. P. 275-282.

[10] Камзолов С.К., Новиков С.М., Разумовский А.Н., Ярцев И.М. Исследование влияния лакокрасочных покрытий на молниестойкость авиационных металлических материалов. Наука и техника гражданской авиации. Серия: Летательные аппараты и двигатели. М.: НТРС ЦНТИ ГА, 1982. Вып. 1. С. 17-21.

[11] Разумовский А.Н. Влияние диэлектрических покрытий на молниестойкость обшивки самолета. Экспресс-информация, „Воздушный транспорт“. Отечественный опыт. 1986. Вып. 8. С. 78.

[12] Пат. AR. I 20060022. Памаев А.М, Мехтиев А.Ш., Низамов Т.И., Исаев Э.И. Уплотнительный компаунд Азербайджанская Республика, Государственный комитет по стандартизации, метрологии и патентам. Официальный бюллетень „Промышленная собственность“. Бюлл. 1. 11.04.2006. C. 28.

[13] ГОСТ 31993-2013 (ISO 2808:2007) Материалы лакокрасочные. Определение толщины покрытия.

[14] ГОСТ 14236-81. Пленки полимерные. Метод испытания на растяжение.

[15] ГОСТ 28840-90. Машины для испытания материалов на растяжение, сжатие и изгиб. Общие технические требования.

[16] Кужсекин И.П. Испытательные установки и измерения на высоком напряжении. М.: Энергия, 1980.

[17] ГОСТ 1516.2-97. Электрооборудование и электроустановки переменного тока на напряжение 3 кВ и выше. Общие методы испытаний электрической прочности изоляции.

[18] ГОСТ Р 52082-2003. Изоляторы полимерные опорные наружной установки на напряжение 6-220 кВ.

[19] Базелян Э.М., Райзер Ю.П. Искровой разряд. М.: МФТИ, 1997. $320 \mathrm{c}$. 